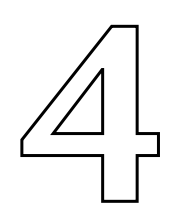

\title{
Young children's perceptions of their classroom environment: perspectives from England and India
}

\author{
Mallika Kanyal and Linda Cooper
}

\section{Overview}

This chapter explores the use of different participatory methods to enable us to understand children's perceptions of their school experience. It is based on a study carried out with 12 5-6-year-old children from a primary school in south-east England and 15 5-6-yearold children from a school in northern India. The chapter's aims are twofold: first, to discuss the use of qualitative participatory methods children's drawings, children's pair interviews and photographic/video evidence of different areas of the class/setting, taken/videoed by children themselves - as a means to understand children's perceptions of their classroom experience and, second, to interpret children's meaning making of their classroom experience using the culturalhistorical framework of understanding human behaviour.

Growing awareness and understanding of children as actors in their own right is becoming widely accepted within societies and education communities (Kellett, 2011). This potentially enables us to ascertain the needs of the child through their own eyes and not necessarily only through adult interpretation. By gaining the insights of the children themselves into 
their school environment, we can explicitly address the individual and collective needs of children. The creation of a learning environment developed in collaboration with children is, therefore, more likely to be sympathetic and responsive to their needs and aspirations.

Lancaster (2006) believes that children's experiences and voices must be understood as perceived by the child and not how adults infer or interpret them. Practitioners may, however, find it challenging to attend to a number of voices in the classroom. Integral to the challenge is the knowledge of using appropriate methods, both visual and verbal, to encourage all children to participate in discussions affecting their experiences at school. Further to this is the intersection of unique personality traits which may differ for confident, vocal children to those of quiet, shy children. These traits influence children's will and level of participation and also the explicit and implicit expression of ideas within the classroom. The explicit voices are relatively easier to attend to but the implicit voices may need some form of adult interpretation. This then raises the question of whether some form of subjectivity is bound to emerge if we are to fully understand the explicit and/or implicit voices of children.

Children's participation is, therefore, a contested notion. One way of simplifying this is to consider participation as being conceived and constructed within the social-cultural context of any given society. The social constructs, for example, of childhood, vary among communities. They influence our policies and practices and how we encourage and guide children to participate in decisions affecting their lives. The implications of these policies to practice are that children's participation may range from tokenism to intermediate and true to partnership experiences.

Since our study is based on two different socio-cultural contexts, the English and the Indian, it is important to first look closely at the two educational contexts. In the current English system, there are a range of frameworks to guide children's agency and participation in different social and educational institutions, for example the English Early Years Foundation Stage (DCSF, 2008a) and Every Child Matters (ECM) (DCSF, 2003). Together, such programmes or frameworks are intended to be representative of cultural beliefs and values, attempting to put children at the heart of everything that professionals do with young children. These beliefs and values can then be seen as being passed on to the younger generation through opportunities for guided participation (Rogoff, 2003). Critics have, however, expressed their concern over the difference between real participation and tokenism where children and children's images can be used merely for decoration purposes (Hart, 1997). Also, there is no guarantee that such policies will empower children's position as there could be other external and internal constraining factors which may influence the translation of national policies into local practice. 
India, on the other hand, could be perceived as going through a phase of change, both socially and educationally. The education system is in the process of implementing the newly conceived National Curriculum Framework (NCF, 2005) which is receiving a mixed response from the professionals concerned. It is welcomed by some (for example, Kumar, 2005) but, at the same time, critics have questioned the translation of this framework into reality due to the weak infrastructure of schools (Deepa, 2005; Sharma, 2000).

The differences in such social contexts influence the opportunities for guided participation and interaction that children may experience within their communities. These opportunities are expressed through everyday routine practices, for example in the school and family, which can be perceived as positive or negative (depending upon our ethnocentric views). However, on the precautionary side, it is important to remember that it is not fair to label people solely according to their membership of perceived cultural community(ies). These processes often intersect with children's individual personality and influence the way they behave and learn.

\section{Why should we listen to children?}

We believe that the recognition of children's agency and children's voices is a direct result of the ratification of the United Nations Convention on the Rights of the Child (UNCRC, 1989) by all major countries in the world (except the USA and Somalia). It has been a major milestone in creating an attitudinal shift which emphasises the need to listen to children. Articles 12,13 and 14 of the UNCRC quite specifically acknowledge children's legal right to participate in their own learning and how they should be given autonomy as a recognised group of social actors in their own right (UNCRC, 1989). But despite this recognition of children as social actors and their legal entitlement to participate in activities that affect their lives, there is still contention about children's meaningful participation in their own education and related processes (McNaughton et al., 2007). There is scepticism, especially about young children's lack of competence and experience to participate. This, on the other hand, could be interpreted as a lack of adults' confidence and will to share their authority with children. Such resistance often creates barriers in developing children's participative capacity. Adoption of this idea into reality and everyday practice, therefore, can challenge our familiar ways of thinking about adult-child relationships. It can demand new role expectations for adults who take care of children (Woodhead, 2005).

Relating this argument to the education context, various authors have used different approaches and metaphors to describe levels of children's participation, such as the Mosaic Approach (by Clark et al., 2003), Ramps (by Lancaster, 2006) and Ladder (by Hart, 1997). These models could be understood and applied both at the policy and practice level. For example, Ramps and Ladder 
could be used as an evaluative framework to help institutions and practitioners guide their own policies and practice. The Mosaic Approach, on the other hand, can give practitioners practical ideas on how to encourage and include children in planning and designing their own learning environments.

With this in mind, our study uses both traditional and contemporary methods to identify children's perceptions of their learning environment. This can be seen as the first step for planning and implementing any change to the classroom learning environment. Environments thus created in conjunction with children and for children are believed to be much more sympathetic and responsive to their needs.

Ethical issues were duly considered, especially those involving the children's consent, given the nature of the study's focus.

\section{Listening to children's voices: some interactive methods}

This section outlines our small-scale study, carried out in summer 2009, involving 12 5-6-year-old children from a primary school in south-east England and 15 5-6-year-old children from a school in north India. Our aim, as the title suggests, was to capture young children's perceptions of their classroom environments in these two culturally different countries and compare these views using the socio-cultural perspective of understanding human behaviour. Three qualitative participatory methods - children's drawings, photographic/video evidence of different areas of the class or setting recorded by children themselves and children's pair interviews - were used. It was believed that this triangulation of participatory methods would give children multiple opportunities to express their perceptions of the school environment and also give our study findings validity.

\section{Method 1: Children's drawings}

Children's drawings have been a subject of controversy in the academic community. Martindale (2008) argues that children's drawings cannot possibly be viewed as a reliable source of information, including children's perceptions of themselves, or anything else. He believes that, through their drawing, children may not always represent their perceptions but, rather, a 'wish'. But other researchers have shown the effectiveness of children's drawings in helping educators and other professionals to understand the lives of children in school and related settings (for example, Walker, 2008; Anning and Ring, 2004; Bonoti et al., 2003; Weber and Mitchell, 1995). These settings form part of children's cultural locale which informs their meaning making (Kendrick and McKay, 2004). Hence, children's drawings are much more than a simple representation of what they see before them and can be better understood as ways in which they are making sense (Anning and Ring, 2004). 
We, therefore, believe that children's drawings can be a very useful tool to help us capture individual children's perceptions of their school experience. It also enables us to listen to the voices of children with different personalities, both vocal and shy. Martindale's (2008) perspective of children's drawing as representative of their 'wish' and not 'perception' is also a useful one. We believe that it is imperative for a practitioner to actually acknowledge both children's 'perceptions' and 'wishes'. By doing so, they get the opportunity to enter into children's mental spaces of their 'ideal school' experience.

With this in mind, children in settings in both England and India were asked to draw two pictures using a research instrument designed by Armstrong (2007). This included a picture of:

- their 'actual school experience'

- what they anticipate as their 'ideal school experience'.

It was suggested to the children that, in both drawings, they put themselves, their teacher and a friend or two. Children were asked to make sure that everyone was shown to be doing something and also, if possible, to label the people in their drawing. This guidance was intended to be facilitative to encourage children to draw various aspects of their experiences. There is some contention about adult manipulation of children's voices to adhere to an adult-dominated agenda of quality and performance. The idea here was to capture children's thinking while they were engaged in the process of drawing their pictures. The children were only given guidance and were free to draw what they liked to represent their thinking about their 'actual' and 'ideal' school experiences. The narratives from children about their drawings were recorded whilst they were actively engaged in the process.

\section{Method 2: Photographic and video evidence}

The use of cameras and video cameras has been a popular method of engaging children with contemporary research. There are clear benefits of using such methods as they can be fun for children and informative for adults. It can also help to overcome the limitation of drawing by capturing the action(s), which is not always possible to capture through drawings (Punch, 2002).

The children in our research were given disposable cameras to take pictures of different areas within their classroom and school - inside or outside - capturing areas which they particularly liked or disliked. Areas of the school which repeatedly appeared in the photographs were placed into the broad categories of 'learning environment' and were later used as prompts during the interview process. The running commentaries (video recordings) were also carefully noted, identifying children's likes and dislikes and the reasons 
behind these. The whole process of taking photographs aimed at encouraging children's participation and active involvement. It was framed by an approach using visual methodologies which recognise that young people are experts in their own worlds and have distinctive ways of seeing (Burke, 2005).

Whilst recognising the value of contemporary research instruments, it is important to note that such photographs/video clips can be representative of only the current learning theme which may not necessarily last for the whole year. Therefore, it is advisable to integrate similar tools into routine evaluative plans, for example to collect children's views each time there is a change in the theme of classroom learning environment. Not every setting, however, will be in a position to buy such expensive equipment. There are other interactive methods, like interviews or small group work, which could be equally effective in understanding children's perceptions of their classroom environment.

\section{Method 3: Interviewing young children}

Interviews with young children can yield valid results, provided attention is paid to certain preconditions (Brooker, in Macnaughton et al., 2004; Formosinho and Araújo, 2006). Four such preconditions which we would like to refer to are, first, the context in which interviews are carried out; second, the number of children to be interviewed at a given time; third, the medium used for the interview; and fourth, the number of questions asked.

Applying these principles to our research, interviews were carried out with children in the school context (within their classroom). This is perceived to have favoured the interview process as a familiar environment elicits better interview utterances (longer, clearer, more complex, more thoughtful). Children were also interviewed in pairs by using a toy telephone as the interview medium. The interview was kept short to a minimum number of questions (three in this case) and children's voices were tape-recorded to allow researchers to revisit their response at a later stage. The questions asked were as follows:

1. Why do you think you come to school?

2. What do you like about coming to school or into your class?

3. Is there anything you do not like about your school or your class?

\section{Being reflexive: interpreting an essential component of listening}

Listening, as Clark et al. (2003) suggest, is not all about hearing but also interpreting, constructing meaning and responding. Therefore, it is essential to interpret the findings and develop a shared understanding of 
the information gathered by using different participatory methods with young children. It is a reflexive process which can only promote good practice.

Analysis and interpretation of children's drawings in both countries indicate that their 'actual school experience' is academically driven, representing a traditional view of classrooms where the teacher takes the authority position and children comply with instructions (Lodge, 2007; Weber and Mitchell, 1995). The majority of the children drew their 'actual' experience as sitting inside the classroom and doing 'class work' (mostly literacy and numeracy activities) whilst the teacher was sitting at the front of the classroom, taking the authority position. A few children drew their actual experience as 'playing' outside with friends, with the teacher being in close vicinity. The teacher was viewed as either 'watching', 'playing', 'guiding' or 'helping' them in their play activities. This could be argued to represent their implicit acceptance of a teacher's significant role, even in peer-dominated play experiences. The children's 'actual' experiences are, therefore, influenced by both the explicit and implicit presence of a teacher who seemed to be illustrating both dominating and facilitative roles in shaping children's everyday school experiences.

The ideal school experience portrays a mixed image of children's perceptions in the schools in England and India. In England, children unanimously express their wish to be outside, engaged in a range of activities with their teacher and friends. Children in India, however, gave a mixed response, some expressing their wish to be outside, just like children in England, whilst others struggled to draw the difference between the actual and ideal school experience. This can be perceived as the gap in their understanding about the abstract term 'ideal school', which may be a result of the lack of opportunities and experiences available to them to draw upon, or else they were 'conditioned' to believe this is what happens within the 'ideal' context. Their representations were more focused on the structure variables and facilities, such as an ICT room, good quality fans and lighting, general cleanliness, etc., which brings our attention to the environment and well-being issues.

Considering these findings from a pedagogic position, children at school in India did not demonstrate variation in child-teacher interaction through their ideal school drawings. The teacher was still the central figure taking the traditional authority role, whereas the children at school in England, through their ideal school experience drawings, showed the teacher either in a supervisory role or as non-existent in their drawings. This shows that the children took our instructions for their drawings as guidance only as they still chose not to include teachers in their ideal school drawings. Children's ideal school experiences, therefore, could be depicted in an emancipation continuum where some chose to be free from the frameworks of school and teacher and others 
chose to imagine their experiences within the given structures and boundaries of school.

The second method, the photographic and video evidence, was used to categorise the learning environments, which constituted the themes shown in Table 4.1 .

Table 4.1 Categorising the learning environment: classroom/school areas as photographed or videoed by children at schools in India and England

\begin{tabular}{cll}
\hline S. no. & Class/school area (England) & Class/school area (India) \\
\hline 1 & The white board & The blackboard \\
2 & The book area & The teachers' sitting area (desk and chair) \\
3 & Phonics area & Play area (one climbing frame) \\
4 & Outside (playground) & Outside (playground) \\
5 & (Various) class displays & (One) display area \\
6 & Work table & Reading/writing on the desk \\
7 & Colouring time/area & Colouring time \\
8 & Craft area & Fans and tube lights \\
9 & Computer area & Windows \\
10 & Puppet area & Friends (friendship) \\
11 & Coat peg area & Bottle (and lunchbox) \\
\hline
\end{tabular}

After categorising photographs into the themes in Table 4.1, children were then asked whether they liked/disliked or were not sure about that area. A majority of the children in England liked all these areas in the classroom and the outside space, with a few not being sure of some displays as 'they were old'; the white board as 'it may involve reading'; the peg area as 'it is boring'; the phonics area as 'it involves sounding out letters'; the puppet area as 'it is boring'; the book area as 'it involves reading'; and the work table as 'it involves studying'.

The majority of the children in India also liked all class/school areas, with a few not being sure of some areas like windows as 'they are not clean'; the outside area as 'it becomes mucky'; and fans and tube lights as 'they throw hot air and the room looks dark at the time of power cut'.

However, both in England and India, there was no resounding dislike for any of the areas. Children's perceptions of why they liked these areas was a general like towards activities that underpinned the working of these areas, such as colouring, making a display, reading interesting books, playing football and doing art and craft activities.

Analysis thus drawn from their identified theme areas suggests that children at school in England appear to be having access to a range of activities/areas, whereas children at school in India have few things that constitute their learning environment. These perceived affordances could limit or encourage children's interaction with the environment, which is believed to shape children's perceptions of their everyday school experiences. 


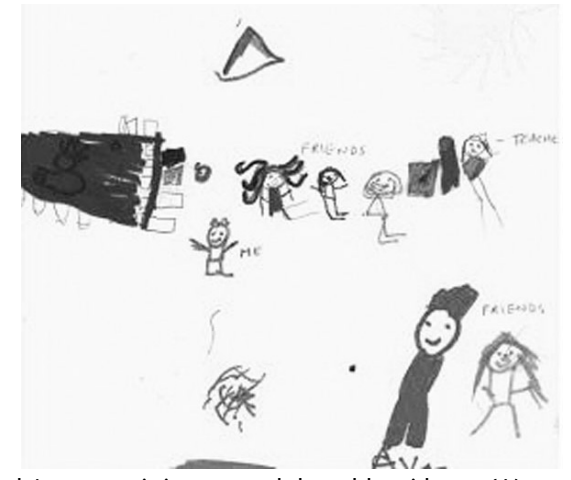

My friends Yasmin and Anna are sitting around the table with me. We are putting our hands up to answer the question by the teacher. Teacher is teaching the class and standing by the white board.

Figure 4.1 'Actual' school drawing, England

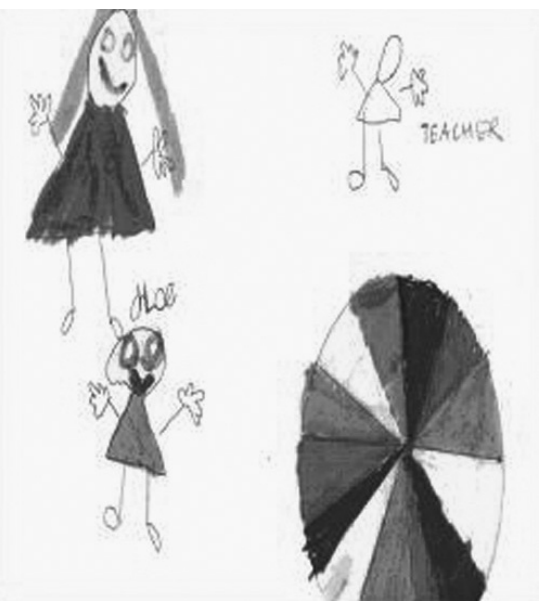

In this picture I am outside with my friends. Caitlin and Ella are playing outside near the swings. I am getting on the roundabout. Teacher is watching us play outside.

Figure 4.2 'Ideal' school drawing, England

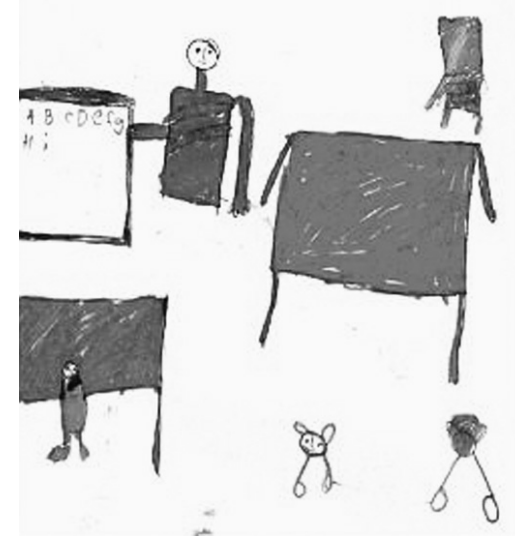

The teacher is teaching us and we are sitting on desks and chairs. My friends are playing in the classroom.

Figure 4.3 'Actual' school drawing, India 


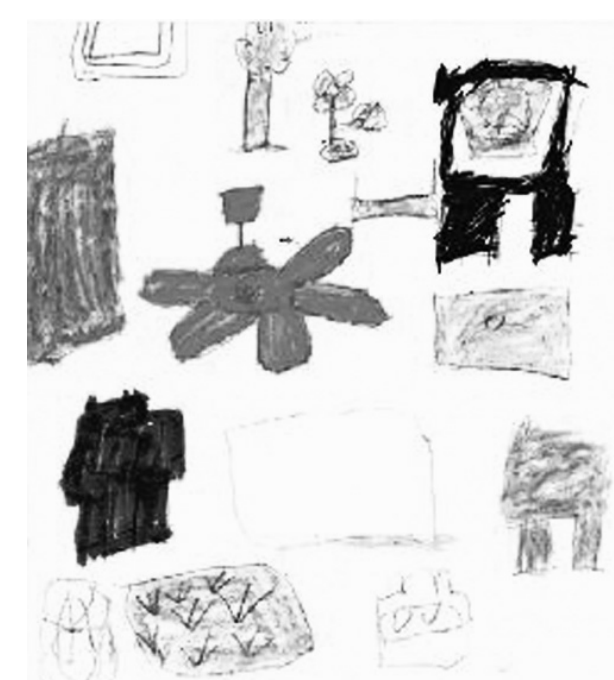

In my ideal school there are nice trees, table, fans and my books.

Figure 4.4 'Ideal' school drawing, India

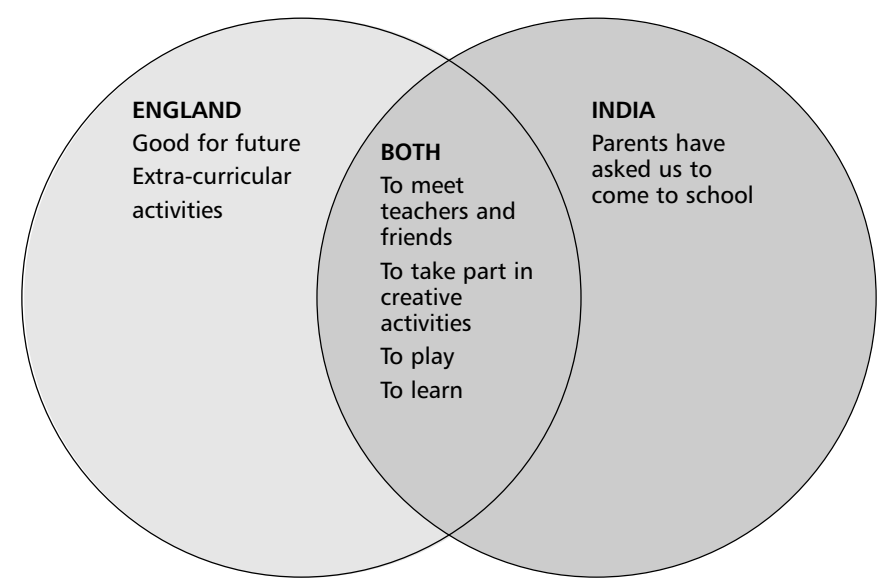

Figure 4.5 Why do you think you come to school?

On the basis of the third and our last method, interviews, it is clear that children's perceptions of why they attended school ranged from adult-imposed reasons (to improve their future or to comply with parents' wishes) to reasons which might be of benefit to themselves (self-gratifying or educational). Interestingly, when questioned on their views on likes and dislikes at school, all of the children expressed suggestions of particular activities in which they like to take part. However, no explicit dislikes were expressed, although mention was made of factors which might cause them physical or emotional harm (mild aggression or discomfort). Findings from both settings are represented in the Venn diagrams below, showing the similarities and differences in children's responses to the interview questions. 


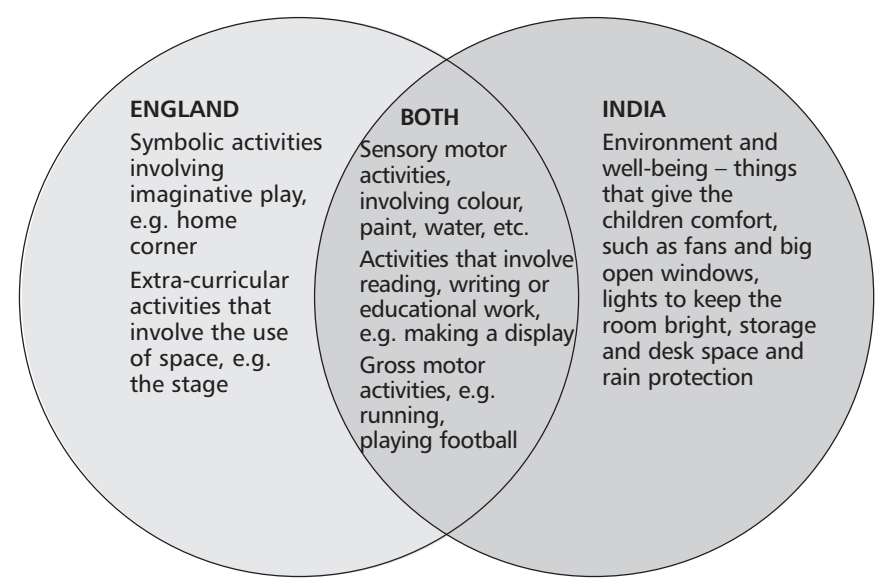

Figure 4.6 What do you like about coming to school or into your classroom?

The responses from the interviews indicate children's liking towards the learning environment, both the objects/people and the processes undertaken by them with their peers and teacher(s).

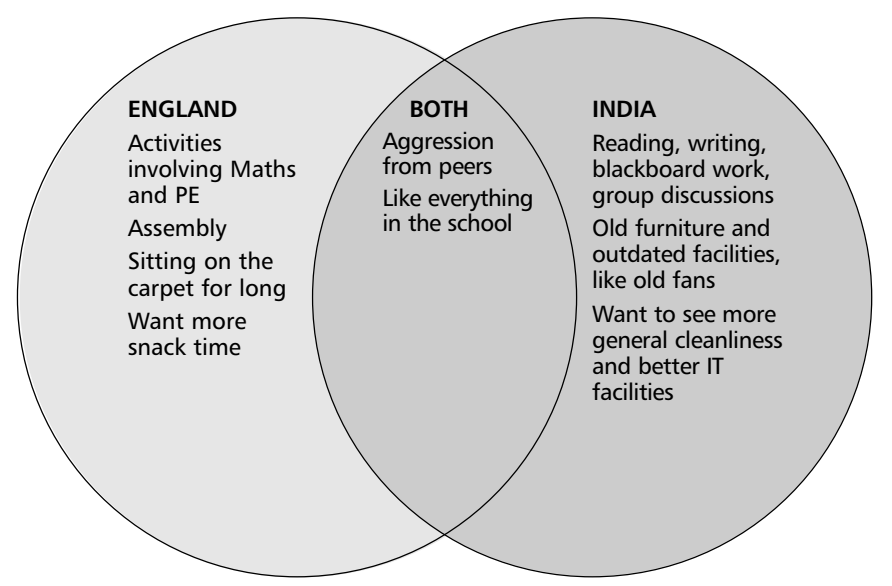

Figure 4.7 Is there anything you don't like about your school or classroom?

\section{Children's perceptions: a socially constructed phenomenon}

Children's perceptions of their school experiences in two different sociocultural contexts (England and India) are analysed using Rogoff's (2003) three planes of analysis (see Figure 4.8).

The first plane is at the personal level where individual children's perceptions are considered at an intrapersonal level. By giving each child the opportunity to take photographs, draw pictures and talk in their own words, we provided them with the tools to participate in expressing their views about the classroom environment. It can be perceived as providing 
the children with a sense of their own agency, enabling them to control and present their viewpoint to us. Concomitantly, it allowed us to capture their understanding of the school environment, which potentially could be used as a reflective tool to plan (more) responsive and meaningful learning environments for the children.

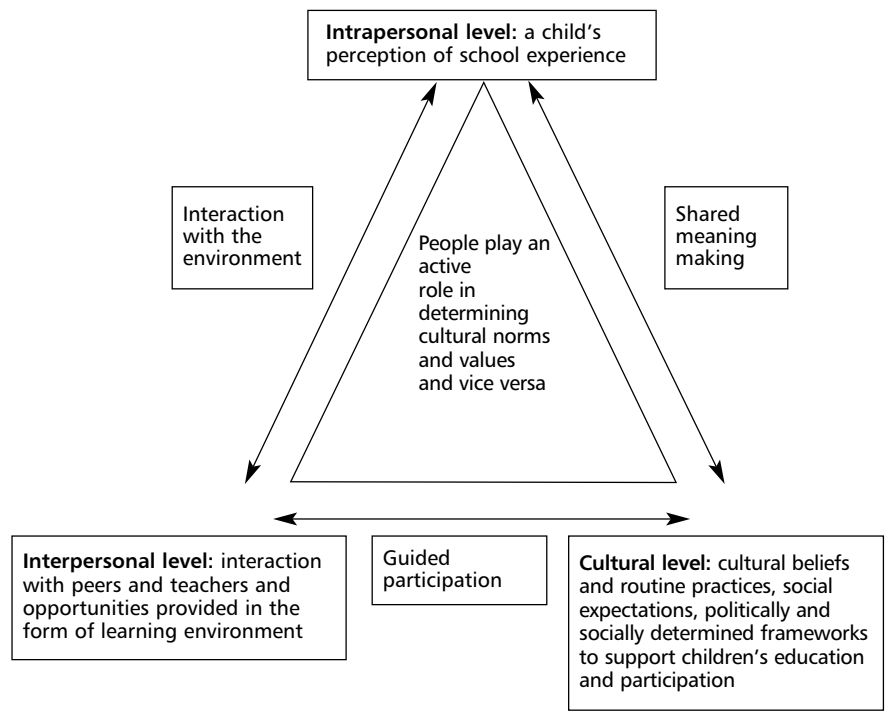

Figure 4.8 Insights into children's participation using Rogoff's three planes of analysis

To gain an insight into the wider factors that affect the development of children's perceptions, Rogoff's second plane of analysis, called the social or interpersonal level, is used. This includes children's involvement in socially constructed collective activities (Rogoff, 2003). Children actively make meaning from the experiences gained by interacting with their environment (as shown in Figure 4.3). The environment can take the shape and form of structures, for example the external building and its surroundings (Thelin and Yankovich, cited in Carney-Strange and Banning, 2001) and the processes involved when different objects and/or people interact within this environment. Interaction with the environment can range from over stimulation to minimal or no stimulation. These interactive operations are highly important as it is during these processes that intersubjectivity, or shared understanding, is established between participants. But these joint purposes and goals can only be realised when children's views are heard. Such guidance principles can now be perceived as universal, though their precise forms vary from community to community.

This brings us to the third and final plane of analysis which is at the cultural level. At this level, children are believed to learn their cultural practices and tools through guided participation in cultural endeavours (Rogoff, 2003). We must, therefore, recognise the cultural nature of everyday 
practices, including pedagogical processes. The forms of these processes vary within different societies resulting in different sets of experiences for its groups of people. However, we must not forget that individuals (including children) have agency and that they can choose how to behave (Rogoff, 2003). This suggests that culture is not always a linear phenomenon; it can 'create people' but, at the same time, can be modified or changed by the action of its groups of people.

\section{Implications for practice}

At the pedagogic level, our findings from this small study lead us to suggest:

- Our methods to understand children's perceptions of their school experience are relatively easy to replicate.

- Drawings, small group interviews and digital technology can be used effectively to capture children's perceptions about their (learning) environments.

- These resources allow a dialogue between the teacher and the group of children to give them agency to participate.

- Attending to voices does not always mean that a process needs to be changed or that final decisions are to be made by the children. Instead, it means that children are being given opportunities to enter into relational dialogic spaces with adults, the purpose of which is to make them feel confident and valued members of the group.

- Children are active people, capable of engaging in the development of their own learning, which occurs at three different levels: intrapersonal, interpersonal and cultural.

- Adults need to provide opportunities through guided participation to encourage children to develop shared understanding about the cultural tools and norms of their community but, at the same time, be aware of the fact that an individual can belong to multiple communities.

- Rather than looking at culture as a static social process, we must focus on individual people's involvement and participation in cultural communities. 


\section{Summary}

From a practical viewpoint, the findings from the research highlight the importance of understanding children's voices as perceived by the child and not by how adults infer. However, attention must be paid to both the explicit and implicit voices of children.

We feel there is a need to celebrate good practice. The fact that the children did not cite explicit dislikes may be a favourable reflection on the environment that was created for them. This positive response from the hardest critics of all - the children - should empower practitioners. In a context which is bombarded with reporting, paperwork and inspections to measure improving outcomes, this can only be a good thing.

\section{Questions for discussion}

1. In what ways are you able to give children a voice in their learning and environments?

2. What do you think you would learn from children if they made drawings of their environment and relationships? How might this enable you to understand children's perceptions of their learning environment?

3. What other media/method do you think could be used effectively to encourage children to enter into the dialogic relation space with their teacher(s) to share their views about their learning environment, both in its structures and processes?

\section{References and suggested further reading}

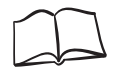

Entries in bold are further reading.

Anning, A. and Ring, K. (2004) Making Sense of Children's Drawings. Maidenhead: Open University Press.

Armstrong, D. (2007) Classroom Visions: Efficient and Effective Ways to Differentiate Education. Available at: www.classroomvisions.com (accessed 10 January 2011).

Bonoti, F., Plousia, M. And Fotini, G. (2003) Graphic Indicators of Pedagogic Style in Greek Children's Drawings. Perceptual and Motor Skills, 97: 195-206.

Burke, C. (2005) Play in Focus: Children Researching Their Own Spaces and Places for Play. Children, Youth, Environments, 15(1): 27-53.

Carney-Strange, C. and Banning, J.H. (2001) Education by Design. San Francisco, CA: Jossey-Bass.

Clark, A., McQuail, S. and Moss, P. (2003) Exploring the Field of Listening to and Consulting with Young Children. London: DfES Research Report 445.

Deepa, A. (2005) New Curriculum Framework: A Few Chapters Short. Available online at: www.indiatogether.org/2005/dec/edu-ncf2005.htm (accessed 14 November 2009).

Department for Children, Schools and Families (DCSF) (2003) Every Child Matters. Available online at: http://www.dcsf.gov.uk/everychildmatters/about/aboutecm (accessed 12th November 2009). 


\section{2}

Department for Children, Schools and Families (DCSF) (2008) Statutory Framework for the Early Years Foundation Stage. Nottingham: DCSF.

Formosinho, J. and Araújo, S.B. (2006) Listening to Children as a Way to Reconstruct Knowledge about Children: Some Methodological Implications. European Early Childhood Education Research Journal, 14(1): 21-31.

Hart, R.A. (1997) Children's Participation: The Theory and Practice of Involving Young Citizens in Community Development and Environmental Care. London: Earthscan.

Kellett, M. (2011) Accessing Children's Voices and Experiences. In J. Moyles, J. Georgeson and J. Payler (eds) Beginning Teaching, Beginning Learning (4th edn). Maidenhead: Open University Press.

Kendrick, M. and McKay, R. (2004) Drawings as an Alternative Way of Understanding Young Children's Constructions of Literacy. Journal of Early Childhood Literacy, 4(1): 109-28.

Kumar, K. (2005) New Curriculum Framework: A Few Chapters Short. Available at: www.indiatogether.org/2005/dec/edu-ncf2005.htm (accessed 14 November 2009).

Lancaster, Y.P. (2006) RAMPS: A Framework for Listening to Children. London: Daycare Trust. Available online at: www.daycaretrust.org.uk/mod/fileman/ files/RAMPS.pdf (accessed 20 September 2009).

Lodge, C. (2007) Regarding Learning: Children's Drawings of Learning in the Classroom. Learning Environment Research, 10: 145-56.

MacNaughton, G., Hughes, P. and Smith, K. (2007) Young Children's Rights and Public Policy: Practices and Possibilities for Citizenship in the Early Years. Children and Society, 21: 458-69.

Macnaughton, G., Rolfe, S. and Siraj-Blatchford (eds) (2004) Doing Early Childhood Research: International Perspectives on Theory and Practice. Buckingham: Open University Press.

Martindale, D. (2008) One Picture May Not Be Worth 1000 Words: Children's Drawings, Perceptions of Themselves and Their Families. Available online at: http://business. highbeam.com/437254/article-1G1-192338114/one-picture-may-not-worth1000-words (accessed 15 March 2011).

National Curriculum Framework (NCF) (2005) National Council of Educational Research and Training. Available online at: www.ncert.nic.in/html/pdf/schoolcurriculum/ framework05/prelims.pdf (accessed 15 November 2009).

Punch, S. (2002) Research with Children: The Same or Different From Research with Adults? Childhood, 9(3): 321-41.

Rogoff, B. (2003) The Cultural Nature of Human Development. Oxford: Oxford University Press.

Sharma, R. (2000) Decentralisation, Professionalism and the School System in India. Economic and Political Weekly, 35(42): 3765-74.

United Nations Convention on the Rights of the Child (UNCRC) (1989) Available online at: www.unicef.org.uk/Documents/Publication-pdfs/crcsummary. pdf?epslanguage $=$ en (accessed 15 January 2011).

Walker, G. (2008) Working Together for Children: A Critical Introduction to Multi-agency Working. London: Continuum.

Weber, S. and Mitchell, C. (1995) 'That's Funny, You Don't Look Like a Teacher': Interrogating Images and Identity in Popular Culture. Abingdon: RoutledgeFalmer. Available online at: http://site.ebrary.com/lib/anglia/Doc?id=10058250\&ppg=17 (accessed 10 February 2010).

Woodhead, M. (2005) Early Childhood Development: A Question of Rights? International Journal of Early Childhood, 37(3): 79-98. 